\title{
Successful Long-term Management with a Single Administration of Tri-weekly Nab-paclitaxel in a Patient with Advanced Gastric Cancer with Peritoneal Dissemination
}

\author{
Daisuke Matano, Toshikazu Moriwaki, Yoshitaka Tange, Yusuke Niisato, \\ Masamichi Yamaura, Masaomi Nagase, Daisuke Suganuma, Kaoruko Takagi Taketa, \\ Kentaro Iwai, Chiaki Enami, Yoshiyuki Yamamoto and Ichinosuke Hyodo
}

\begin{abstract}
Nanoparticle albumin-bound (nab)-paclitaxel has shown promising activity in advanced gastric cancer treatment. We herein report a case of advanced gastric cancer involving long-term management with a single administration of nab-paclitaxel. A 71-year-old man diagnosed with advanced gastric cancer with malignant ascites was treated with nab-paclitaxel as a second-line chemotherapy. He refused treatment continuation because of various severe toxicities in the first treatment cycle; he was therefore followed-up without any further treatments. Despite this, no disease progression was observed over 9 months. After progression, he received dose-dense paclitaxel, but he did not respond to this treatment and eventually died.
\end{abstract}

Key words: gastric cancer, nab-paclitaxel, dissemination, ascites

(Intern Med 56: 921-923, 2017)

(DOI: 10.2169/internalmedicine.56.7783)

\section{Introduction}

Paclitaxel, a microtubule-stabilizing agent, is a key drug for advanced gastric cancer treatment. Dose-dense paclitaxel-containing regimens are widely used as secondline chemotherapy to treat patients with advanced gastric cancer (AGC) who experienced failure after fluoropyrimidine and platinum (1). However, steroids and antihistamines, such as H1- and H2-receptor blockers, must be administered to patients prior to paclitaxel because Cremophor $^{\circledR}$, a solvent polyethoxylated castor oil contained in the paclitaxel formulation, causes allergic and hypersensitivity reactions. Nanoparticle albumin-bound ( $\mathrm{Nab}$ )-paclitaxel is a nanoparticle preparation consisting of paclitaxel and human serum albumin that can be administered without the steroids and anti-histamines (2). Nab-paclitaxel is a current treatment option for breast cancer and non-small cell lung cancer $(3,4)$. Additionally, it has shown promising activity for treating patients with previously treated advanced gastric cancer in a Japanese phase II trial (5). We herein report a patient with AGC who received only one administration of nab-paclitaxel and showed long-term disease control.

\section{Case Report}

A 71-year-old man with an Eastern Cooperative Oncology Group (ECOG) performance status (PS) of 0 was diagnosed with AGC, as he had a moderately differentiated Bormann type 1 adenocarcinoma in the posterior wall of the upper gastric corpus with synchronous liver and peritoneal metastasis. He joined a clinical trial and received S-1 plus leucovorin as first-line chemotherapy. He maintained a partial response for one year, and then malignant ascites appeared without obvious progression of other lesions (Figure A). His ECOG PS was 0 at the time of first progression. His findings on blood examinations, including carcinoembryonic antigen and carbohydrate antigen 19-9, were all within normal 

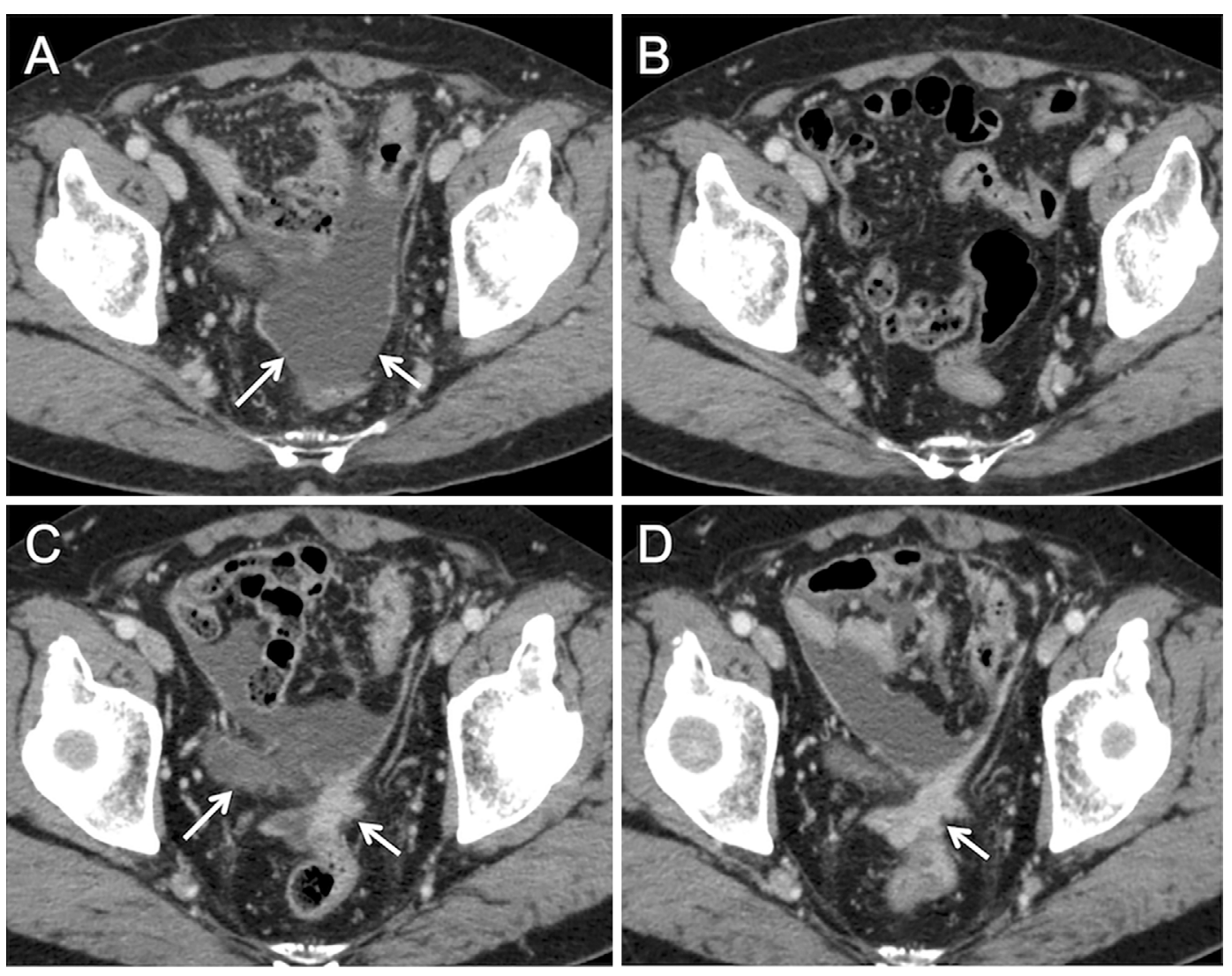

Figure. (A) Pelvic computed tomography before nab-paclitaxel. Ascites were observed in the pelvic area (arrows). (B) Two months after a single administration of nab-paclitaxel, ascites no longer appeared in the pelvic area. (C) Peritoneal dissemination and ascites reappeared (arrows) 9.4 months after the single nab-paclitaxel administration. (D) Peritoneal dissemination increased (arrow) two months after administration of dose-dense paclitaxel.

ranges, excluding his serum hemoglobin value. He received nab-paclitaxel $\left(260 \mathrm{mg} / \mathrm{m}^{2}\right.$ on day 1 , every 21 days $)$ as second-line chemotherapy. During the first cycle of treatment, various toxicities occurred, including grade 4 neutropenia, grade 3 peripheral sensory neuropathy (PSN), grade 3 myalgia, grade 2 constipation, grade 2 anorexia, and grade 2 oral mucositis. Most toxicities recovered to grade 0 or 1 within 7 days from their onset, including neutropenia. However, the patient experienced PSN for 67 days before recovery to grade 1 . Although treatment with a reduced dose of nab-paclitaxel was recommended, he refused treatment continuation. He received follow-up without any treatments. His ascites disappeared on CT scan 2 months after administration (Figure B), and no disease progression was observed for 9.4 months. However, peritoneal dissemination with ascites reappeared (Figure $\mathrm{C}$ ), and he was treated with dosedense paclitaxel $\left(80 \mathrm{mg} / \mathrm{m}^{2}\right.$ on days 1,8 , and 15 every 21 days) because he refused reintroduction of nab-paclitaxel. No severe toxicities were observed (maximum grade of toxicities were grade 0 neutropenia, grade 2 myalgia, grade 2 PSN, and grade 1 anorexia), and the treatment was continued. However, peritoneal dissemination and ascites increased two months after the administration was started (Figure D). He received 5-fluorouracil plus leucovorin as third-line chemotherapy, but the ascites increased. He died 17.8 months from administration of nab-paclitaxel.

\section{Discussion}

Tri-weekly nab-paclitaxel treatment resulted in a median time to response and median progression-free survival of 36 days (range, 29-57 days) and 2.9 months (95\% CI, 2.4-3.6), respectively, in a phase II study for patients with previously treated AGC (5). We encountered a patient with AGC who maintained disease control over 9 months despite receiving just one administration of nab-paclitaxel. His cancer cells, especially peritoneal cancer cells, might have been highly sensitive to paclitaxel. Generally, malignant ascites in various cancers are associated with a poor prognosis (6). Indeed, the median overall survival is only 3 to 4 months when AGC patients with malignant ascites do not receive any chemotherapy (7). The single administration of nabpaclitaxel appeared to be quite effective, as he survived more than 1.5 years from its administration.

Interestingly, dose-dense paclitaxel after disease progression was not effective. There may be several reasons for this result. First, it was reported in preclinical and clinical studies that conventional paclitaxel might have a smaller volume of paclitaxel distribution in the tumor than nabpaclitaxel $(8,9)$. This difference may be important for its 
therapeutic effectiveness. Second, a single dose of dosedense paclitaxel might not have been enough. In this patient, no neutropenia was observed during dose-dense paclitaxel treatment. Because neutropenia has been shown to be correlated with survival among patients with AGC treated with a standard dose of dose-dense paclitaxel (10), a randomized phase II trial was performed to evaluate the efficacy of doseescalated dose-dense paclitaxel guided by neutropenia, compared with standard-dose dose-dense paclitaxel for patients with previously treated AGC (11). The efficacy data favored patients who received dose-escalated dose-dense paclitaxel. Finally, the progressive cancer cells might not have been sensitive to paclitaxel. Unfortunately, it was unclear whether or not his cancer cells were paclitaxel-resistant, because they were not assessed at the time of disease progression. An ongoing randomized phase III trial (ABSOLUTE) is evaluating the overall survival after treatment with tri-weekly paclitaxel or dose-dense nab-paclitaxel compared with dose-dense paclitaxel as second-line chemotherapy for patients with AGC (12). This trial may answer some of these questions.

The patient experienced some severe adverse events in the first cycle. The most common grade 3 or 4 toxicities in a Japanese phase II trial for advanced gastric cancer were neutropenia in $49 \%$ of patients and PSN in $24 \%$ of patients, including myalgia in $5.5 \%$ of patients (5). In cases with severe toxicities, dose reduction can be used to identify a tolerated dose for the patient. However, in this patient, treatment continuation would have been difficult, as the various severe toxicities, including PSN and myalgia, were observed simultaneously. The median reported recovery time from grade 3 to grade 1 PSN is 39 days (5), but recovery from grade 3 PSN in this case took longer than in the previous report. Prevention and treatment for PSN or acute pain syndromes, such as myalgia and arthralgia, should be considered, as those toxicities reduce patients' quality of life. Although several randomized trials have been performed, optimal management has not been clarified (13).

In conclusion, we herein report the case of a patient with AGC who demonstrated long-term tumor control with a single administration of nab-paclitaxel.

The authors state that they have no Conflict of Interest (COI).

\section{References}

1. Kang BW, Kwon OK, Chung HY, Yu W, Kim JG. Taxanes in the treatment of advanced gastric cancer. Molecules 21: E651, 2016.

2. Nyman DW, Campbell KJ, Hersh E, et al. Phase I and pharmacokinetics trial of ABI-007, a novel nanoparticle formulation of paclitaxel in patients with advanced nonhematologic malignancies. J Clin Oncol 23: 7785-7793, 2005.

3. Gradishar WJ, Tjulandin S, Davidson N, et al. Phase III trial of nanoparticle albumin-bound paclitaxel compared with polyethylated castor oil-based paclitaxel in women with breast cancer. J Clin Oncol 23: 7794-7803, 2005.

4. Socinski MA, Bondarenko I, Karaseva NA, et al. Weekly nabpaclitaxel in combination with carboplatin versus solvent-based paclitaxel plus carboplatin as first-line therapy in patients with advanced non-small-cell lung cancer: final results of a phase III trial. J Clin Oncol 30: 2055-2062, 2012.

5. Sasaki Y, Nishina T, Yasui $\mathrm{H}$, et al. Phase II trial of nanoparticle albumin-bound paclitaxel as second-line chemotherapy for unresectable or recurrent gastric cancer. Cancer Sci 105: 812-817, 2014.

6. Ayantunde AA, Parsons SL. Pattern and prognostic factors in patients with malignant ascites: a retrospective study. Ann Oncol 18: 945-949, 2007.

7. Fang N, Zhang HQ, He B, et al. Clinicopathological characteristics and prognosis of gastric cancer with malignant ascites. Tumour Biol 35: 3261-3268, 2014.

8. Desai N, Trieu V, Yao Z, et al. Increased antitumor activity, intratumor paclitaxel concentrations, and endothelial cell transport of cremophor-free, albumin-bound paclitaxel, ABI-007, compared with cremophor-based paclitaxel. Clin Cancer Res 12: 1317-1324, 2006.

9. Sparreboom A, Scripture CD, Trieu V, et al. Comparative preclinical and clinical pharmacokinetics of a cremophor-free, nanoparticle albumin-bound paclitaxel (ABI-007) and paclitaxel formulated in Cremophor (Taxol). Clin Cancer Res 11: 4136-4143, 2005.

10. Shitara K, Matsuo K, Takahari D, et al. Neutropenia as a prognostic factor in advanced gastric cancer patients undergoing secondline chemotherapy with weekly paclitaxel. Ann Oncol 21: 24032409, 2010.

11. Shitara K, Yuki S, Tahahari D, et al. Randomised phase II study comparing dose-escalated weekly paclitaxel vs standard-dose weekly paclitaxel for patients with previously treated advanced gastric cancer. Br J Cancer 110: 271-277, 2014.

12. Koizumi W, Morita S, Sakata Y. A randomized Phase III trial of weekly or 3-weekly doses of nab-paclitaxel versus weekly doses of Cremophor-based paclitaxel in patients with previously treated advanced gastric cancer (ABSOLUTE Trial). Jpn J Clin Oncol 45: 303-306, 2015.

13. Fernandes R, Mazzarello S, Majeed H, et al. Treatment of taxane acute pain syndrome (TAPS) in cancer patients receiving taxanebased chemotherapy: a systematic review. Support Care Cancer 24: 1583-1594, 2016.

The Internal Medicine is an Open Access article distributed under the Creative Commons Attribution-NonCommercial-NoDerivatives 4.0 International License. To view the details of this license, please visit (https://creativecommons.org/licenses/ by-nc-nd/4.0/).

(C) 2017 The Japanese Society of Internal Medicine http://www.naika.or.jp/imonline/index.html 